09,14

\title{
ИК-Фурье спектроскопическое исследование кинетики фазового перехода I рода в тридекановой кислоте $\mathrm{CH}_{3}\left(\mathrm{CH}_{2}\right)_{11} \mathrm{COOH}$
}

\author{
(C) В.А. Марихин ${ }^{1}$, Л.П. Мясникова ${ }^{1}$, Е.И. Радованова ${ }^{1}$, Б.З. Волчек ${ }^{2}$, Д.А. Медведева ${ }^{2}$ \\ ${ }^{1}$ Физико-технический институт им. А.Ф. Иоффре РАН, \\ Санкт-Петербург, Россия \\ ${ }^{2}$ Институт высокомолекулярных соединений РАН, \\ Санкт-Петербург, Россия \\ E-mail: V.Marikhin@mail.ioffe.ru
}

(Поступила в Редакцию 7 июля 2016 г.)

Методом ИК-Фурье спектроскопии изучены структурные изменения в кристаллических сердечниках ламелей тридекановой кислоты $\mathrm{CH}_{3}\left(\mathrm{CH}_{2}\right)_{11} \mathrm{COOH}$ при нагревании от $T_{1}=13.5^{\circ} \mathrm{C}$ до $T_{2}>T_{m}=41.6^{\circ} \mathrm{C}$. Анализировалось поведение полос маятниковых (область $720 \mathrm{~cm}^{-1}$ ) и деформационных (область $1470 \mathrm{~cm}^{-1}$ ) колебаний $\mathrm{CH}_{2}$-групп в метиленовых отрезках тридекановой кислоты. Показано, что в области фазового перехода I рода $\left(T_{s-s} \sim 36^{\circ} \mathrm{C}\right)$ в узком температурном интервале $\left(\Delta T_{1} \leq 1 \mathrm{~K}\right)$ происходит постепенная трансформация исходной триклинной субъячейки в гексагональную субъячейку. Рассмотрен механизм этого перехода с позиции теории диффузионных фазовых переходов I рода.

Работа выполнена при финансовой поддержке Российского фонда фундаментальных исследований (код проекта 16-03-00493).

DOI: 10.21883/FTT.2017.02.44056.285

\section{1. Введение}

Известно [1-2], что в циклах нагревание-охлаждение различных длинноцепочечных молекулярных кристаллов (ДМК) (н-алканы, н-алканоспирты, $\alpha, \omega$-алканодиолы, моно- и дикарбоновые алканокислоты и др.) наблюдается 2 типа фазовых переходов:

1) твердофазный (структурный) переход I рода (ФП-1) при температурах, заметно ниже температуры плавления $T_{m}$, и

2) переход II рода (ФП-2) типа порядок-беспорядок, связанный с плавлением кристаллов при $T_{m}$.

Методом ДСК показано [2-4], что в ДМК фазовый переход ФП-1 происходит в достаточно узких температурных интервалах $\Delta T$, но отличных от нуля, как это должно быть в случае идеальных монокристаллов [5]. Подобные переходы с $\Delta T \geq 1 \mathrm{~K}$ получили название размытых фазовых переходов I рода и обозначаются как $\Lambda$-переходы [6-8].

Для описания размытых фазовых переходов предложена теория самосогласованного поля [7], в рамках которой структурный переход ФП-1 рассматривается как флуктуационное возникновение наноразменрых зародышей новой фазы в объеме исходной с последующим ростом зародышей за короткие промежутки времени. В результате новая фаза распространяется на весь объем предыдущей при изменении температуры в узком интервале $\Delta T \geq 1 \mathrm{~K}$.

С целью доказательства справедливости данного подхода при изучении ДМК в работе методом ИК-Фурьеспектроскопии исследовались структурные перестроения в области ФП-1 при нагревании молекуляр- ных кристаллов монокарбоновой тридекановой кислоты $\mathrm{CH}_{3}\left(\mathrm{CH}_{2}\right)_{11} \mathrm{COOH}$.

\section{2. Эксперимент}

Исследовали коммерческие продукты тридекановой кислоты без дополнительной очистки. Тонкие пленки для ИК-измерений получали путем высушивания 5\% раствора тридекановой кислоты в хлороформе на поверхности пластинок $\mathrm{KBr}$ при комнатной температуре. Далее пленки в зазоре между двумя пластинками $\mathrm{KBr}$ помещались в термокювету и нагревались до температуры выше температуры плавления (для наших образцов кислоты $T_{m}=314.6 \mathrm{~K}$ [3]) и затем медленно охлаждались до комнатной температуры. Толщина образцов составляла $10-20 \mu \mathrm{m}$. Запись ИК-Фурье спектров в области частот $400-5000 \mathrm{~cm}^{-1}$ осуществлялась на спектрометре Bruker IFS-88 фирмы Bruker, Германия, при ступенчатом повышении температуры с шагом $0.2 \mathrm{~K}$ до подхода к области ФП-1 и с шагом $0.1 \mathrm{~K}$ в области самого ФП-1. Температура измерялась дифференциальной ТХК с точностью $0.05 \mathrm{~K}$.

Перед записью спектра образец выдерживался $10 \mathrm{~min}$ при выбранной температуре для достижения теплового равновесия. Число накоплений сигнала составляло 50.

\section{3. Результаты и их обсуждение}

С помощью оптической и электронной микроскопии установлено $[9,10]$, что макроскопические длинноцепочечные молекулярные кристаллы, в том числе и монокарбоновых кислот, состоят из стопок наслоенных 
друг на друга тонких ламелярных (пластинчатых) кристаллов, толщина которых (единицы $\mathrm{nm}$ ) сопоставима с длиной молекулы кислоты. Трехмерно-упорядоченные кристаллические сердечники отдельной ламели образованы из метиленовых последовательностей. Чередующиеся прослойки между кристаллическими сердечниками в стопках состоят либо из двух контактирующих концевых метиленовых групп соседних ламелей, объединенных ван-дер-ваальсовыми силами, либо из циклических димеров, возникающих за счет образования водородных связей между концевыми карбоксильными группами молекул в соседних ламелях [11]. Рентгенодифракционные исследования в области малых и больших углов дифракции позволяют выявить особенности укладки ламелей друг относительно друга, типы взаимного расположения молекул друг относительно друга, а также типы взаимного расположения молекул в кристаллических сердечниках отдельных ламелей.

В молекулярных кристаллах рассматривают 2 типа кристаллических ячеек:

1) основную ячейку (main cell), характеризующую способ укладки ламелей друг относительно друга [12];

2) субъячейку (sub-cell), описывающую характер укладки молекул относительно друг друга в кристаллическом сердечнике индивидуальной ламели [13].

Как основные, так и субъячейки могут быть орторомбическими, моноклинными или триклинными, при этом не обязательно одной и той же сингонии одновременно, поскольку во всех длинноцепочечных молекулярных кристаллах, содержащих нечетное число атомов углерода в цепи, молекулы в сердечнике расположены под некоторым углом по отношению к поверхности ламелей.

Сведения о типе основной ячейки обычно получают при сопоставлении больше- и малоугловых рентгенодифракционных данных с учетом геометрических размеров молекул $[1,2]$. Экспериментальные данные о типе субъячеек можно получить не только на основании большеугловых рентгенодифракционных данных, но также и при анализе ИК-спектров поглощения, соответствующих разным типам колебательных мод от протяженных метиленовых последовательностей в кристаллических сердечниках ламелей [14-16]. Кроме того, важные сведения о строении межламелярных прослоек могут быть получены при анализе специфических ИК-полос поглощения, соответствующих колебательным модам от концевых $\mathrm{CH}_{3}$-групп и различным модам колебаний карбоксильных групп, объединенных в циклические димеры.

Таким образом, анализ поведения ИК-полос поглощения при варьировании температуры позволит проследить за трансформациями ламелярной структуры, в том числе при ФП-1, происходящими как в сердечниках ламелей, так и в их поверхностных слоях.

В данной статье мы рассматриваем изменения в кристаллической части ламелей тридекановой кислоты при нагревании образцов от температуры $13.5^{\circ} \mathrm{C}$ до температуры плавления. Структурные изменения, происходящие в поверхностных слоях, будут рассмотрены в последующих статьях.

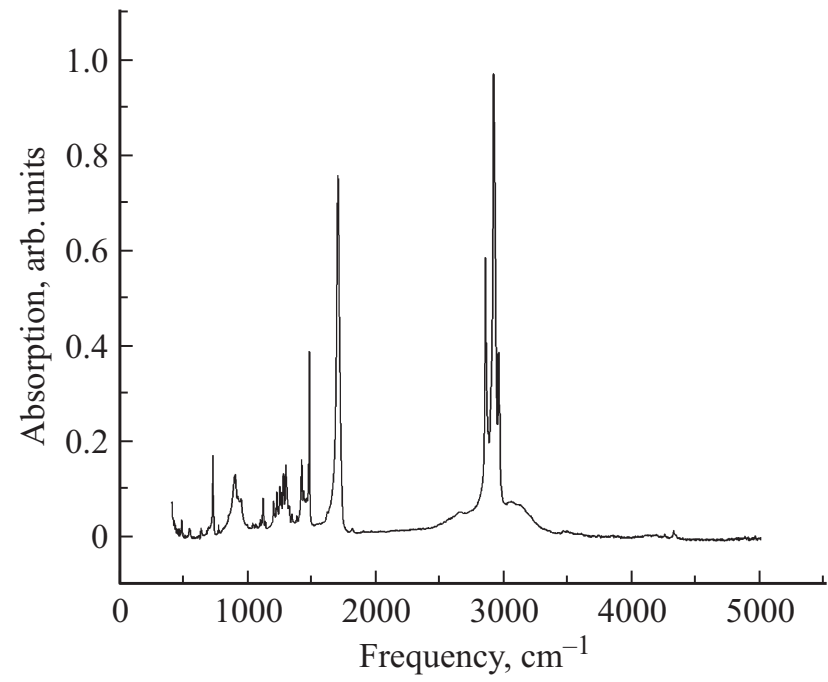

Рис. 1. ИК-спектр поглощения тридекановой кислоты при комнатной температуре во всем исследованном частотном диапазоне $\left(400-5000 \mathrm{~cm}^{-1}\right)$.

На рис. 1 приведен ИК-Фурье-спектр тридекановой кислоты при комнатной температуре в исследованном частотном диапазоне $400-5000 \mathrm{~cm}^{-1}$. В спектре наблюдаются интенсивные характеристические полосы поглощения, соответствующие различным модам колебаний как метиленовых последовательностей, так и колебаниям концевых групп. Частоты наблюдаемых нами полос поглощения находятся в соответствии с литературными данными [17,19 и многочисленные ссылки в статьях].

В данной статье будет анализироваться температурное поведение только полос поглощения, соответствующих маятниковым (область 700-720 $\mathrm{cm}^{-1}$ ) и деформационным (область $1460-1480 \mathrm{~cm}^{-1}$ ) колебаниям $\mathrm{CH}_{2}$ групп в метиленовых последовательностях в кристаллических сердечниках ламелей. Эти данные позволят проанализировать характер структурных трансформаций в субъячейках кристаллов тридекановой кислоты в процессе развития фазового перехода ФП-1, так как все полосы поглощения в обычно используемом диапазоне частот $\left(400-5000 \mathrm{~cm}^{-1}\right)$ связаны только с локальными колебаниями в достаточно коротких метиленовых последовательностях [20].

На рис. 2-5 приведены температурные изменения ИК-спектра поглощения, соответствующие полосам маятниковых (рис. 2, 3) и деформационных (рис. 4, 5) колебаний $\mathrm{CH}_{2}$-групп в кристаллических сердечниках ламелей тридекановой кислоты.

Известно [14-20], что на основании анализа особенностей поведения полос поглощения в области маятниковых и деформационных колебаний $\mathrm{CH}_{2}$-групп можно делать вывод о характере взаимной укладки метиленовых отрезков, т.е. о типе симметрии кристаллических субъячеек и ее изменениях, как в процессе кристаллизации, так и при фазовых переходах ФП-1 и ФП-2 различных ДМК. 


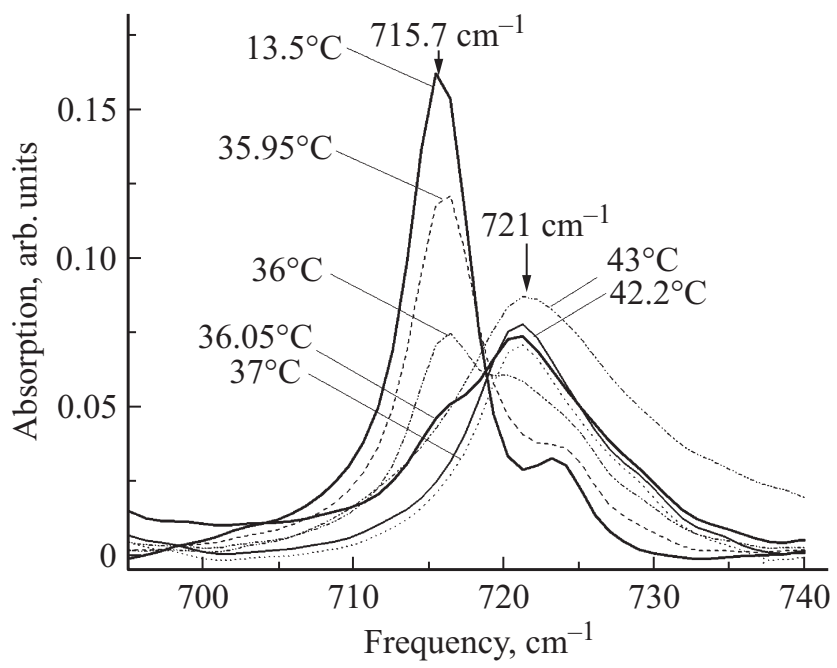

Pис. 2. Температурная зависимость спектра поглощения тридекановой кислоты в области маятниковых колебаний.

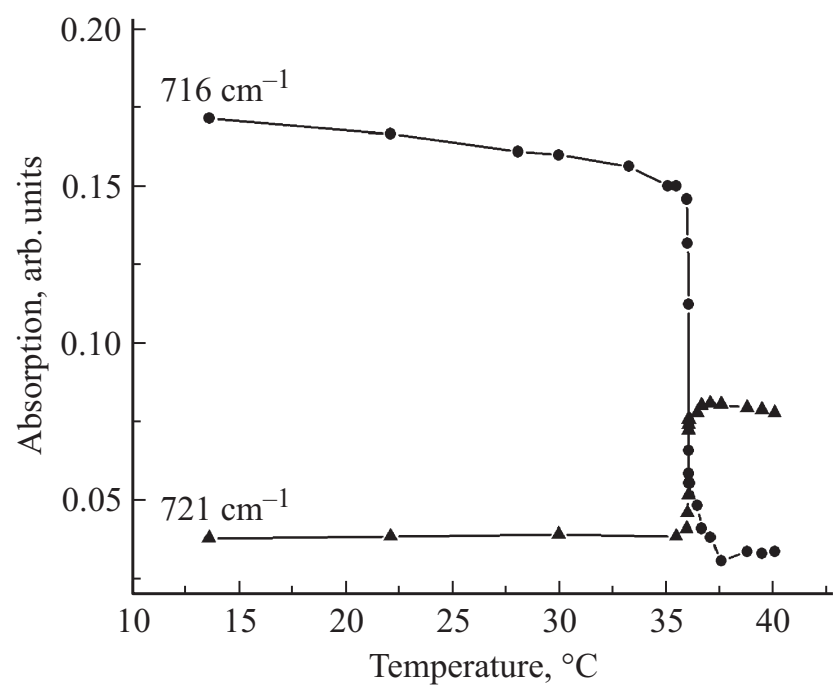

Pис. 3. Температурная зависимость оптической плотности в максимумах полос поглощения маятниковых колебаний.

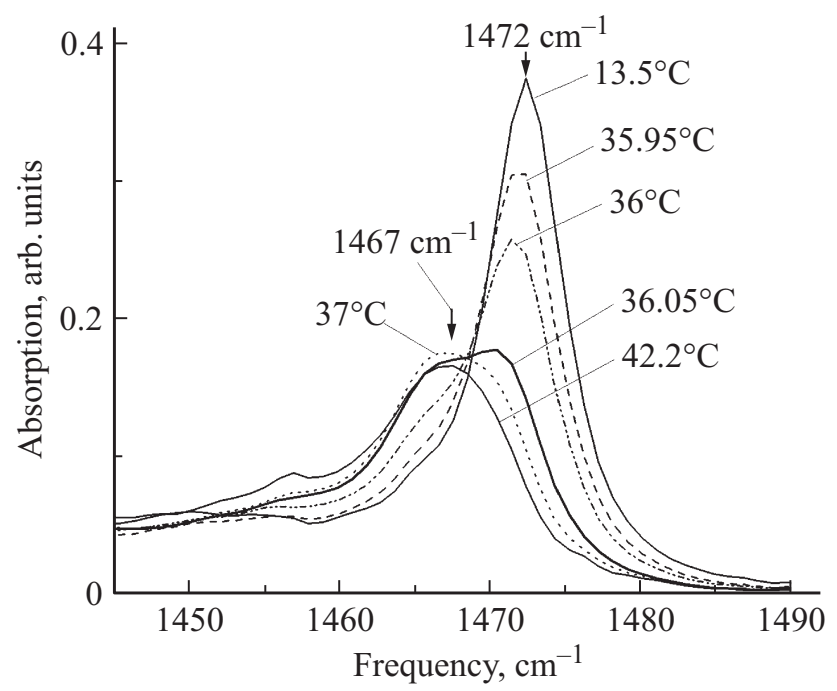

Рис. 4. Температурная зависимость спектра поглощения в области деформационных колебаний.
Наличие при комнатной температуре интенсивных одиночных полос поглощения при $v=715.7 \mathrm{~cm}^{-1}$ (маятниковые колебания $\mathrm{CH}_{2}$-групп, рис. 2) и $v=1472 \mathrm{~cm}^{-1}$ (деформационные колебания $\mathrm{CH}_{2}$-групп, рис. 4) позволяет предполагать, что в наших образцах, полученных при охлаждении расплава тридекановой кислоты до комнатной температуры, образовались ламели, в кристаллических сердечниках которых метиленовые последовательности образуют субъячейки триклинной симметрии.

В работе [21] на основании рентгенографических исследований показано, что при кристаллизации тридекановой кислоты как из расплава, так и из растворов в различных растворителях, в отличие от многих гомологов монокарбоновых кислот, всегда образуются кристаллы типа $A^{\prime}$ (по классификации [22]), в которых как основная, так и субъячейка имеют триклинную симметрию.

В триклинных субъячейках оси и плоскости метиленовых транс-зигзагов всех молекул параллельны друг другу. Поскольку в триклинной примитивной ячейке содержится одна эффективная центросимметричная молекула, включающая две метиленовые группы, то симметрия ИК-колебаний в таком случае будет приблизительно такой же, как и для индивидуальной выпрямленной молекулы с симметрией $\mathrm{C}_{2 h}$. Следовательно, для каждого фундаментального колебания, в том числе для маятниковых и деформационных, должна присутствовать только одна компонента (отсутствует давыдовское расщепление, наблюдаемое в орторомбической субъячейке [20]).

В литературе отсутствуют ИК-спектроскопические данные для тридекановой кислоты в области деформационных и маятниковых колебаний $\mathrm{CH}_{2}$-групп. В работе [18] исследовалась лишь область спектра, в которой расположены полосы поглощения от карбоксильных групп, объединенных в димерные кольца.

При исследовании других гомологов $H$-монокарбоновых кислот $\left(\mathrm{C}_{18} \mathrm{H}_{35} \mathrm{O}_{2}\right.$ [23] и $\mathrm{C}_{16} \mathrm{H}_{33} \mathrm{O}_{2}$ [24]), а также

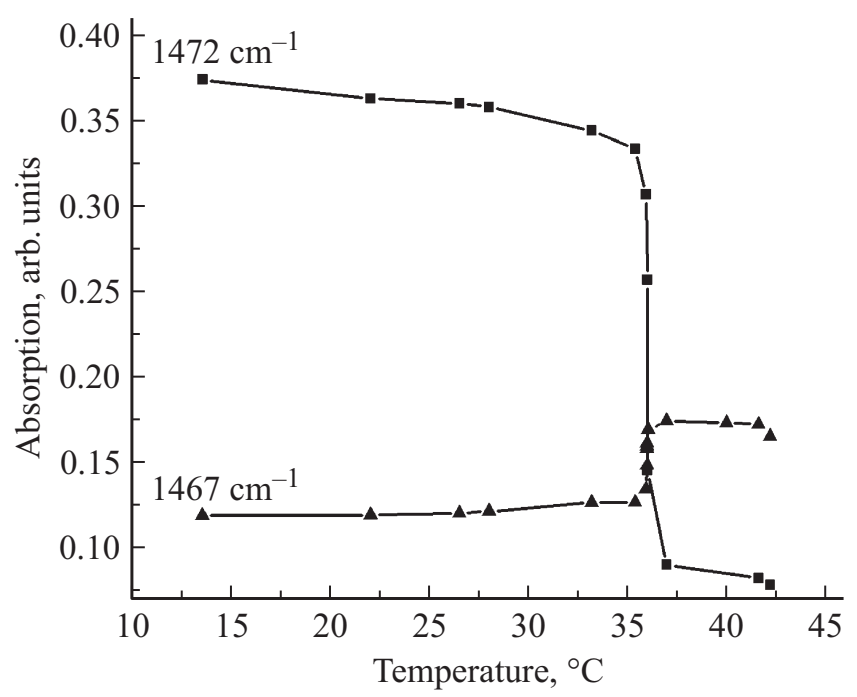

Рис. 5. Температурная зависимость оптической плотности в максимумах полос поглощения деформационных колебаний. 
Значения частот маятниковых и деформационных колебаний в различных соединениях с триклинной (N $1-13)$ и гексагональной (N 14-19) субъячейками

\begin{tabular}{|c|c|c|c|c|}
\hline $\mathrm{N}$ & Соединение, химическая формула & Ссылки & $v \mathrm{CH}_{2}$-rock & $v \mathrm{CH}_{2}$-bend \\
\hline \multicolumn{5}{|c|}{ Кислоты } \\
\hline 1 & Тридекановая кислота $\mathrm{CH}_{3}\left(\mathrm{CH}_{2}\right)_{11} \mathrm{COOH}$ & [Данные авторов статьи] & 715.7 & 1472 \\
\hline 2 & Октадекановая кислота $\mathrm{CH}_{3}\left(\mathrm{CH}_{2}\right)_{16} \mathrm{COOH}$ & {$[23]$} & 717 & 1468 \\
\hline 3 & Гептадекановая кислота СН3(СН2)14СООН & {$[24]$} & 718 & 1468 \\
\hline 4 & Серия метил-разветленных октадекановых кислот & {$[25,26]$} & 720 & - \\
\hline 5 & Ненасыщенная транс-8-октадекановая кислота & {$[27]$} & 719 & 1469 \\
\hline \multicolumn{5}{|c|}{ н-Алканы — твердые } \\
\hline 6 & $\mathrm{C}_{16} \mathrm{H}_{34}$ & \multirow[t]{3}{*}[28]{} & \multirow[t]{3}{*}{715} & \multirow[t]{3}{*}{-} \\
\hline 7 & $\mathrm{C}_{22} \mathrm{H}_{46}$ & & & \\
\hline 8 & $\mathrm{C}_{24} \mathrm{H}_{50}$ & & & \\
\hline 9 & $\mathrm{C}_{18} \mathrm{H}_{38}$ & [29] & 718 & 1472 \\
\hline \multicolumn{5}{|c|}{ н-Алканы — расплав } \\
\hline 10 & $\mathrm{C}_{21} \mathrm{H}_{44}$ & {$[19]$} & 720 & \multirow[t]{2}{*}{-} \\
\hline 11 & $\mathrm{C}_{23} \mathrm{H}_{48}$ & {$[32]$} & 721 & \\
\hline \multicolumn{5}{|c|}{ н-Алканы - низкая ММ, жидкие при $T_{\text {room }}$} \\
\hline 12 & $n=10-15$ & [33], [9] & 722 & 1467 \\
\hline \multicolumn{5}{|c|}{ н-Алканы — жидкости или растворы } \\
\hline 13 & $n=6-34$ & {$[34],[10]$} & 720 & 1467 \\
\hline \multicolumn{5}{|c|}{ н-Алканы - гексагональная субъячейка } \\
\hline 14 & $\mathrm{C}_{24} \mathrm{H}_{50}$ & [35] & 720 & 1466 \\
\hline 15 & $\mathrm{C}_{28} \mathrm{H}_{58}$ & & & \\
\hline 16 & $\mathrm{C}_{29} \mathrm{H}_{60}$ & & & \\
\hline 17 & $\mathrm{C}_{19} \mathrm{H}_{40}$ & & & \\
\hline 18 & $\mathrm{C}_{21} \mathrm{H}_{44}$ & & & \\
\hline 19 & $\mathrm{C}_{17}-\mathrm{C}_{27}$ & {$[36,37],[13,14],[19]$} & $720-721$ & 1468 \\
\hline
\end{tabular}

ряда метил-разветвленных октадекановых кислот $[25,26]$ и ненасыщенной транс-8-октадекановой кислоты [27], были обнаружены триклинные субъячейки, для которых значения частот для одиночных пиков в области маятниковых и деформационных колебаний приведены в таблице. Здесь же приведены данные для частот маятниковых и деформационных колебаний для ряда четных $\boldsymbol{H}$-алканов, кристаллизующихся с образованием триклинной субъячейки из метиленовых последовательностей [28-31]. Обращает на себя внимание широкая вариация значений частот как маятниковых $\left(715-722 \mathrm{~cm}^{-1}\right)$, так и деформационных $\left(1468-1475 \mathrm{~cm}^{-1}\right)$ колебаний в различных соединениях, в которых метиленовые последовательности в закристаллизованном состоянии образуют триклинную субъячейку.

В работах $[19,20,28,32-34]$ отмечают, что имеется хорошая корреляция между положением полосы поглощения в области $v \sim 720 \mathrm{~cm}^{-1}$ и типом субъячейки, построенной из метиленовых последовательностей. Это определяется зависимостью потенциальной энергии мо- лекул в равновесном поле кристалла, которая в ДМК обусловлена преимущественно силами межмолекулярного ван-дер-ваальсового притяжения в субъячейках. Показано [12,21,34], что наиболее плотная упаковка характерна для триклинных субъячеек, поскольку в этом случае возможно взаимное смещение молекул вдоль всех векторов субъячейки, что и обеспечивает наиболее сильное ван-дер-ваальсовое взаимодействие.

На возможность образования других полиморфных форм (орторомбической, моноклинной, гексагональной и т.д.) и полиморфных превращений, помимо ван-дерваальсового взаимодействия, влияет симметрия молекулы, тип укладки концевых групп, длины метиленовых последовательностей, наличие полярных групп, двойных связей, разветвлений; условия кристаллизации, внешние факторы (температура, давление) и т.д.

Усиление потенциала межмолекулярных взаимодействий в триклинных субъячейках приводит к сдвигу полос фундаментальных маятниковых колебаний в сторону меньших значений частот. Этот эффект обычно наблю- 
дается при переходах от расплава или растворов ДМК в триклинную кристаллическую фазу - в обоих случаях ИК спектр характеризуется одиночными полосами, но значения частот колебаний в максимумах этих полос заметно различаются (см. таблицу). Обычно в расплавах или растворах н-алканов $v_{\text {rock }}\left(\mathrm{CH}_{2}\right) \cong 720-722 \mathrm{~cm}^{-1}$ и $v_{\text {bend }}\left(\mathrm{CH}_{2}\right) \cong 1467 \mathrm{~cm}^{-1}$. Наши исследования тридекановой кислоты дали следующие значения: $v_{\text {rock }}\left(\mathrm{CH}_{2}\right) \cong$ $\cong 715.7 \mathrm{~cm}^{-1}$ и $v_{\text {bend }}\left(\mathrm{CH}_{2}\right) \cong 1472 \mathrm{~cm}^{-1}$, которые заметно отличаются (см. таблицу) от результатов $[23,24]$ для н-монокарбоновых кислот с четным числом углеродных атомов.

Причинами расхождений данных, представленных в таблице, могут быть разные степени плотности упаковки метиленовых последовательностей в исследуемых образцах в зависимости от способов их получения, а также разрешающие способности ИК спектрометров, используемых авторами. Данные, приведенные в таблице, демонстрируют также, что, как и ожидалось, ослабление ван-дер-ваальсового взаимодействия в триклинных ячейках за счет метильных разветвлений $[25,26]$ или при введении двойных связей [27] в метиленовые последовательности (что сопровождается понижением $T_{m}$ в этих образцах) смещает частоту $v_{\text {rock }}\left(\mathrm{CH}_{2}\right)$ в сторону больших частот, в область $v_{\text {rock }}\left(\mathrm{CH}_{2}\right) \cong 719-720 \mathrm{~cm}^{-1}$.

Анализ данных, представленных на рис. 2, показывает, что интенсивность в максимуме полосы $v=715.7 \mathrm{~cm}^{-1}$ лишь немного уменьшается в процессе нагревания от температуры 13.5 до $35.95^{\circ} \mathrm{C}$ (рис. 2, 3), но уже при $T=36.00^{\circ} \mathrm{C}$, т. е. при изменении температуры всего лишь на $\Delta T=0.05^{\circ} \mathrm{C}$, происходит принципиально важное изменение формы полосы $v=715.7 \mathrm{~cm}^{-1}$ резкое падение интенсивности в максимуме полосы $v=715.7 \mathrm{~cm}^{-1}$ и ее раздвоение, связанное с появлением выраженного дополнительного максимума при $v=721 \mathrm{~cm}^{-1}$ (рис. 2, 3). При дальнейшем постепенном повышении температуры до $T=37^{\circ} \mathrm{C}$ полоса $v=715.7 \mathrm{~cm}^{-1}$ полностью исчезает, а вместо нее появляется широкая полоса с максимумом $v=721 \mathrm{~cm}^{-1}$.

В работах [19,20,35-37] показано, что для н-алканов в твердом состоянии одиночная полоса $v=720 \mathrm{~cm}^{-1}$ (см. таблицу) характерна для субъячеек с гексагональной симметрией, впервые рассмотренных в [38].

В этом случае рассматривают плотную упаковку макромолекул, аппроксимируемых эффективными цилиндрическими стержнями, поскольку допускается вращение плоскостей цепей относительно их оси.

Вследствие некоррелированных осцилляций с ограниченной амплитудой относительно среднего положения с минимальным смещением осей молекул, возникает статистическая разориентация взаимного расположения плоскостей макромолекул в матрице кристаллической сердцевины ламелей. При этом сохраняются ван-дерваальсовые контакты между соседями, что обеспечивает (в основном, за счет сил притяжения) сохранение образца в твердой фазе.
Расположение цепей в примитивной гексагональной субъячейке таково, что (как и в триклинной субъячейке) имеется одна эффективная молекула, т.е. каждое фундаментальное колебание имеет только одну компоненту (нет давыдовского расщепления полос колебаний). В гексагональной субъячейке межцепное ван-дерваальсовое взаимодействие существенно ослабляется вследствие увеличения межцепных расстояний за счет теплового расширения, что и приводит к смещению полос маятниковых колебаний к $v=720 \mathrm{~cm}^{-1}$ и деформационных колебаний к $v=1466-1468 \mathrm{~cm}^{-1}$.

Характерно, что (рис. 2) значения частоты в максимуме полосы $v=720 \mathrm{~cm}^{-1}$, ее интенсивность и полуширина не претерпевают значительных трансформаций при дальнейшем нагревании образца вплоть до температуры плавления тридекановой кислоты $\left(T_{m}=41.6^{\circ} \mathrm{C}\right)$, что обусловлено, по-видимому, сравнительно небольшими изменениями параметров гексагональной субъячейки в этом температурном интервале.

Анализ поведения полос деформационных колебаний $\mathrm{CH}_{2}$-групп в области $1450-1490 \mathrm{~cm}^{-1}$ (рис. 4, 5) показывает полностью аналогичный с маятниковыми колебаниями характер изменения ИК спектра в области фазового перехода 1 рода - при увеличении температуры полоса $v=1472 \mathrm{~cm}^{-1}$, характерная для триклинной субъячейки, также постепенно трансформируется в полосу $v=1467 \mathrm{~cm}^{-1}$, свидетельствующую о возникновении и постепенном увеличении числа зародышей с гексагональным типом упаковки метиленовых последовательностей в кристаллической сердцевине ламелей. Этот переход также происходит достаточно резко в том же самом температурном интервале, как и в случае маятниковых колебаний (ср. рис. 5 и 3).

Вместе с тем при температурах заметно выше $T_{m}$, в частности при $T=43^{\circ} \mathrm{C}$ (рис. 2), наблюдается дальнейшая трансформация полосы $v=720 \mathrm{~cm}^{-1}$. Эта одиночная полоса становится существенно более широкой, при этом максимум полосы остается примерно при тех же значениях. Существенное увеличение полуширины полос при $T>T_{m}$ обусловлено усилением вращательной способности молекул и возрастанием числа нерегулярных гош-дефектов различных типов. Однако межцепные расстояния в гексагональной ячейке и в жидком состоянии оказываются примерно одинаковыми [19].

В работах $[32,39,40]$ показано, что в н-алканах с варьируемым числом $\mathrm{CH}_{2}$-групп, находящихся в различных фазовых состояниях (в жидком при малых $n=6-15$; расплавах или растворах при $n$ вплоть до $n=34$ ), частоты маятниковых и деформационных колебаний во всех случаях оказались $v=720-722 \mathrm{~cm}^{-1}$ и $v=1467 \mathrm{~cm}^{-1}$ соответственно (см. таблицу). Это означает, что во всех рассматриваемых случаях ослабленный по сравнению с другими субъячейками эффективный потенциал межмолекулярных взаимодействий оказывается примерно одинаковым, что и обусловливает существенное постоянство частоты маятниковых колебаний $v=720 \mathrm{~cm}^{-1}$, которая характерна для метиленовых транс-последовательностей с числом $\mathrm{CH}_{2}$-групп, начиная с $n \geq 4-5[14,39]$. 


\section{4. Заключение}

Можно заключить, что методом ИК-спектроскопии в процессе нагрева образцов тридекановой кислоты удалось зарегистрировать динамику размытого структурного фазового перехода I рода, а именно постепенную трансформацию исходной триклинной субъячейки в гексагональную субъячейку в очень узком температурном интервале $\Delta T \leq 1 \mathrm{~K}$.

Сам факт перехода из одного типа субъячейки в другой наблюдался ранее в многочисленных работах $[1,18]$ для многих типов длинноцепных молекулярных кристаллов, начиная с ранних работ по рентгеновской дифракции [38].

В наших исследованиях с помощью ИК-спектроскопии обнаружен не описанный в литературе факт одновременного сосуществования в кристаллах тридекановой кислоты в узком температурном интервале двух типов субъячеек - первоначальных триклинных и зарождающихся новых, гексагональных субъячеек, а также возрастание количества последних за счет постепенного „съедания“ первоначальных триклинных субъячеек, как это и рассматривается в теории размытых фазовых переходов I рода [7].

\section{Список литературы}

[1] D.M. Small. The Physcial Chemistry of Lipids. Premium Press, N.Y.-London (1986). 665 p.

[2] В.М. Егоров, В.А. Марихин, Л.П. Мясникова. Высокомолекуляр. соединения А 49, 2182 (2007).

[3] В.М. Егоров, В.А. Марихин, Л.П. Мясникова. Высокомолекуляр. соединения А 53, 1722 (2011).

[4] В.М. Егоров, В.А. Марихин, Л.П. Мясникова. ФТТ 55, 975 (2013).

[5] Л.Д. Ландау, Е.М.Лифшиц. Статистическая физика. Наука, М. (1976). $584 \mathrm{c}$.

[6] М. Фишер. Природа критического состояния. Мир, М. (1973). $240 \mathrm{c}$

[7] Г.А. Малыгин. УФН 171, 187 (2001).

[8] Б.Н. Ролов, В. Э. Юркевич. Физика размытых фазовых переходов. Изд-во Ростов. ун-та, Ростов (1983). 350 с.

[9] S. Amelinckx. Acta Cryst. 9, 217 (1956).

[10] I.M. Dawson. Brit. J. Appl. Phys. 4, 177 (1956).

[11] F. Francis, S.H. Piper, N. Mulkin. Proc. Roy. Soc. A 128, 214 (1930).

[12] А.И. Китайгородский. Органическая кристаллохимия. Изд-во АН СССР. (1955). 558 с.

[13] V. Vang. Acta Cryst. 4, 104 (1951).

[14] R.G. Snyder. J. Mol. Spectr. 7, 116 (1961).

[15] G. Zerby, R. Magni, M. Gussoni, K.H. Moritz, A. Bigotto, S. Dirlikov. J. Chem. Phys. 7, 3175 (1981).

[16] J.L. Koenig. Spectroscopy of polymers. American Chemical Society. (1992). 324 p.

[17] R.F. Holland, J.R. Nielsen. J. Mol. Spectr. 9, 436 (1962).

[18] E. Sydov. Acta Chem. Scand. 7, 1119 (1955).

[19] D. Chapman. J. Chem. Soc. 4489 (1957).

[20] P.C. Painter, M.M. Coleman, J.C. Koenig. The Theory of Vibrational Spectroscopy and Its Application to Polymeric Materials. John Wiley \& Sons, N.Y. (1982). 580 p.
[21] E. Sydov. Arkiv Kemi. 9, 231 (1956).

[22] S.N. Piper, T. Malkin, H.I. Austin. J. Chem. Soc. 2310 (1926).

[23] R.F. Holland, J.R. Nielsen. J. Mol. Spectr. 9, 436 (1962).

[24] R.F. Holland, J.R. Nielsen. Acta Cryst. 16, 902 (1963).

[25] S. Abrahamson. Arkiv Kemi 14, 65 (1959).

[26] S. Abrahamson, J. Fischmeister. Arkiv Kemi 14, 57 (1959).

[27] A.S. Jahn, H. Susi. J. Phys. Chem. 64, 953 (1960).

[28] J.M. Martin, R.W.B. Jonsten, M.J. O’Neal. Spectr. Acta. 12, 12 (1958).

[29] R.F. Holland, J.R. Nielsen. J. Mol. Spectr. 8, 383 (1962).

[30] R.G. Snyder, J.H. Schachtschneider. Spectr. Acta. 19, 85 (1963).

[31] J.H. Schachtschneider, R.G. Snyder. Spectr. Acta. 19, 117 (1963).

[32] G. Ungar, N. Masic. J. Phys. Chem. 89, 1036 (1985).

[33] Eds S. Abrahamson, I. Pascher. Structure of Biological Membranes. Plenum. Press, London. (1977). 580 p.

[34] E. Segerman. Acta Cryst. 19, 789 (1966).

[35] J.R. Nielson, C.E. Hathaway. J. Mol. Spectr. 10, 366 (1963).

[36] H.L. Casal. Can. J. Chem. 61, 1736 (1983).

[37] H.L. Casal, H.H. Mantsch, D.G. Cameron. J. Chem. Phys. 77, 2825 (1982).

[38] A. Muller. Proc. Royal Soc. L. A 138, 5 (1932).

[39] R.G. Snyder. J. Chem. Phys. 47, 1316 (1967).

[40] R.N. Jones. Spectr. Acta. 9, 235 (1957). 